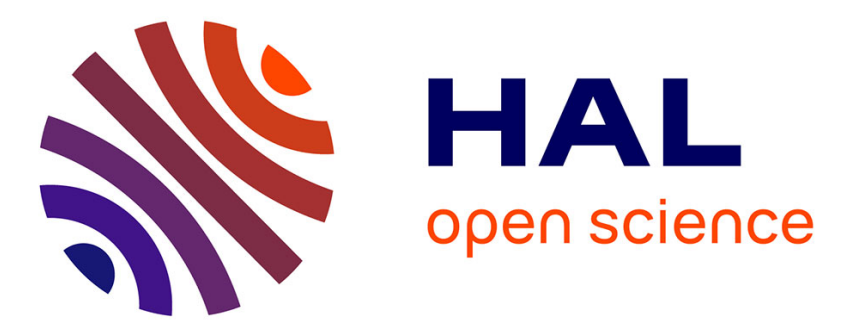

\title{
Activité protéolytique de quelques micro-organismes responsables de la maturation des fromages persillés
}

Giuliano Lusiani, Bruna Bianchi-Salvadori, Pietro Salvadori

\section{To cite this version:}

Giuliano Lusiani, Bruna Bianchi-Salvadori, Pietro Salvadori. Activité protéolytique de quelques microorganismes responsables de la maturation des fromages persillés. Le Lait, 1971, 51 (507), pp.431-436. hal-00928557

\section{HAL Id: hal-00928557 https://hal.science/hal-00928557}

Submitted on 1 Jan 1971

HAL is a multi-disciplinary open access archive for the deposit and dissemination of scientific research documents, whether they are published or not. The documents may come from teaching and research institutions in France or abroad, or from public or private research centers.
L'archive ouverte pluridisciplinaire HAL, est destinée au dépôt et à la diffusion de documents scientifiques de niveau recherche, publiés ou non, émanant des établissements d'enseignement et de recherche français ou étrangers, des laboratoires publics ou privés. 


\title{
Activité protéolytique de quelques micro-organismes responsables de la maturation des fromages persillés
}

\author{
par \\ Giuliano LUSIANI, Bruna BIANCHI-SALVADORI \\ et Pietro SALVADORI \\ Centro Sperimentale del Latte, Milano \\ Directeur Professeur P. SALVADORI
}

\section{Introduction}

Le fromage Gorgonzola, comme les persillés en général, est produit, selon la technologie moderne, avec l'emploi de levains microbiens constitués de ferments lactiques sélectionnés et de moisissures appartenant au genre Penicillium. Ces micro-organismes contribuent à l'affinage du fromage par la flore microbienne présente à la fois dans le lait, dans l'équipement et dans les locaux d'affinage.

Il s'agit donc d'une flore hétérogène, dont le pouvoir protéolytique varie selon l'espèce. Il est connu que les protéolyses les plus marquées se font remarquer là où les moisissures se sont développées plus abondamment et où se trouvent aussi de nombreuses levures. Toutefois on ne doit pas négliger la protéolyse opérée par quelques ferments lactiques, prise en considération par des auteurs divers [1-2-3-4].

D'autre part l'affinage de quelques espèces de fromages se déroule sans l'intervention d'agents protéolytiques violents comme les moisissures ou levures, mais exclusivement par moyen de schizomycètes et pour une petite part avec l'aide des enzymes de la présure [5].

Toutefois, pas toute la flore lactique protéolysante n'est agréable pendant les phases d'affinage ; dans notre travail précédent [6] nous avons en effet remarqué que quelques genres de streptocoques attribuables à l'espèce faecalis produisaient une substance amère, ce qui cause la dépréciation du fromage.

\section{But de la recherche}

Ce travail se rattache à nos études précédentes [7-8-9-10] où nous avons étudié les produits de dégradation des protéines et des grais- 
ses de la part de Penicillium roqueforti que nous considérons logiquement comme le responsable de l'affinage du fromage. A côté de cette recherche nous nous sommes proposés le but d'étudier les caractéristiques de la protéolyse des lactiques (ajoutés ou non) que nous trouvons pendant les phases technologiques du Gorgonzola.

Avant tout nous avons fait un travail préliminaire pour individualiser quelles espèces de lactiques se trouvent en général dans le lait destiné à la fabrication de Gorgonzola. Dans le but de simplifier en partie notre travail, nous avons pris en considération la seule technologie qui prévoit l'emploi de lait pasteurisé.

D'après ces sondages nous avons pu établir que outre, des levains, les lactiques proviennent aussi du lait bien qu'il soit pasteurisé, de la poudre de lait qu'on emploie ordinairement pour la préparation des levains, des récipients, de l'outillage et des locaux d'égouttage (chambre chaude où l'égouttage du caillé continue pendant quelques jours).

En outre il faut rappeler que les levains, qui dans ce cas sont représentés par association de thermophiles, sont habituellement enrichis avec 5-10 p. 100 de flore mésophile.

Les espèces que nous avons étudiées dans le but d'établir le pouvoir protéolytique par la formation des acides aminés, sont les suivantes : Str. lactis, Str. cremoris, Str. diacetilactis, Str. faecalis, Str. faecalis var. liquefaciens, Str. thermophilus, L. bulgaricus, Les deux souches de Str. faecalis sont les mêmes qui ont provoqué des phénomènes de goût amer dans le fromage Gorgonzola.

\section{Méthodes}

Les lactiques isolés du lait et fromage ont été identifiés selon les méthodes biochimiques usuelles; pour les streptocoques des groupes $\mathrm{N}$ et $\mathrm{D}$ de Lancefield on a effectué une ultérieure identification sérologique.

Le lait destiné à l'inoculation des ferments était préparé en partant de poudre de lait écrémé sûrement sans substances antibiotiques et antifermentatives, et dissout dans l'eau distillée à raison de 10 p. 100. Avant l'emploi la poudre de lait était libérée d'éventuelles traces de graisse par extraction avec de l'éther éthylique. Le lait reconstitué était mis dans des erlenmeyers à raison de $400 \mathrm{~cm}^{3}$ chacun, suivi par une stérilisation à $115^{\circ} \mathrm{C}$ pendant $20 \mathrm{mn}$; ensuite on ajoutait du chlorure sodique stérile à raison de 1 p. 100.

$\mathrm{Au}$ moment de l'inoculation on réchauffait le lait à $34^{\circ} \mathrm{C}$ en le maintenant à cette température environ $1 \mathrm{~h}$ après l'inoculation. Ensuite l'inoculation continuait pour $4 \mathrm{j}$ à $22^{\circ} \mathrm{C}$ et à la fin à $4^{\circ} \mathrm{C}$ pour $27 \mathrm{j}$. Parallèlement deux erlenmeyers de lait témoin pas inoculés suivaient le même traitement. De cette manière on a cher- 


\section{Résultats}

Après $4 \mathrm{j}$ d'incubation à $22^{\circ} \mathrm{C}$ les cultures montraient les caractéristiques suivantes :

\section{L. bulgaricus}

Str. thermophilus

Str. lactis

Str. cremoris

Str. diacetilactis

Str. faecalis

Str. faecalis var. liquefaciens

Contrôle témoin

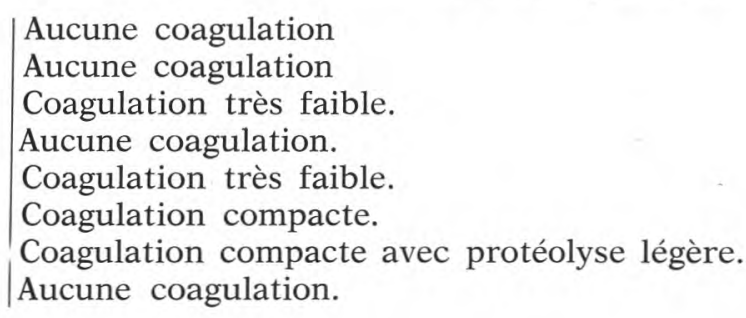

Coagulation compacte avec protéolyse légère.

Aucune coagulation.

Après $31 \mathrm{j}$ d'incubation à $+5^{\circ} \mathrm{C}$ les cultures montraient les caractéristiques suivantes :

\section{L. bulgaricus}

\section{Str. thermophilus}

Str. lactis

Str. cremoris

Str. diacetilactis

Str. faecalis

Str. faecalis var. liquefaciens Contrôle témoin

\begin{tabular}{|c|c|c|c|}
\hline Aspect de la culture & Acidité & $\mathrm{pH}$ & Morphologie \\
\hline $\begin{array}{l}\text { Coagulation faible avec protéo- } \\
\text { lyse légère. }\end{array}$ & 0,50 & 5,20 & $\begin{array}{l}\text { Bâtonnets longs et peu abon- } \\
\text { dants. }\end{array}$ \\
\hline $\begin{array}{l}\text { Coagulation faible avec dépôt } \\
\text { sur le fond. }\end{array}$ & 0,80 & 4,25 & $\begin{array}{l}\text { Chaînettes très longues avec } \\
\text { des coques très ovalaires. }\end{array}$ \\
\hline Coagulation faible et laiteuse & 0,95 & 3,90 & Coques abondants. \\
\hline Coagulation légère sur le fond. & 0,92 & 4,10 & Coques abondants. \\
\hline Coagulation sur le fond. & 0,90 & 4,15 & Coques peu abondants. \\
\hline $\begin{array}{l}\text { Coagulation compacte et géla- } \\
\text { tineuse. Protéolyse partielle. }\end{array}$ & 1,00 & 4,20 & Coques abondants. \\
\hline Protéolyse complète. & 0,60 & 5,65 & Coques abondants. \\
\hline Aucune coagulation. & 0,27 & 6,07 & 一 \\
\hline
\end{tabular}


ché à maintenir les lactiques aux températures qu'ils auraient rencontrées dans les phases technologiques du fromage, avec la seule variation qu'on a arrêté l'essai à 1 mois au lieu de 2 (temps nécessaire pour terminer l'affinage du Gorgonzola). Cet arrêt trouve une raison valable dans le fait qu'après 1 mois l'affinage du Gorgonzola se produit surtout par l'action des Penicillium et en partie aussi des levures. A la fin des 31 j on a déterminé le $\mathrm{pH}$ et l'acidité des cultures ; en outre on a effectué l'évaluation macroscopique du caillé et l'observation microscopique des cultures. Ensuite on a déterminé pour chaque culture la quantité des acides aminés libres produits, en utilisant la méthode décrite par Moore et al. [11-12] avec un analyseur automatique Beckmann $120 \mathrm{~B}$. Pour les acides aminés basiques on a utilisé la colonne courte et pour ceux acides ou neutres la colonne longue.

Tous les essais ont été exécutés en double et les données des tableaux reflètent donc la moyenne des deux résultats.

Le tableau 1 montre les données relatives à la détermination quantitative des acides aminés présents dans les cultures à la fin de l'incubation.

\section{Conclusions}

Il paraît évident que les streptocoques du groupe D déploient une protéolyse plutôt accentuée à température basse et cela nous autorise donc à supposer que leur action a une influence considérable sur l'affinage du Gorgonzola quand ces micro-organismes sont présents en grand nombre. Ce fait n'est absolument pas rare, car dans un de nos travaux précédents nous avons trouvé de fortes charges de streptocoques fécaux dans des fromages mûrs, qui dans la plupart des cas avaient un goût amer.

En général on peut constater que la production d'acides aminés libres est plus élevée pour le $L$. bulgaricus et pour les streptocoques fécaux. Toutefois, dans toutes les espèces étudiées on a trouvé une production de proline, sérine, asparagine + glutamine, isoleucine et phénylalanine. La méthionine libre n'a été trouvée que dans les cultures de $L$. bulgaricus et des streptocoques fécaux, la cystine que dans la culture Str. faecalis var. liquefaciens.

Nous pouvons donc conclure que les schizomicètes dans l'affinage du Gorgonzola déploient, à notre avis, une action acidifiante et protéolysante. Cette thèse est appuyée par la pratique où l'on voit une diminution du $\mathrm{pH}$ dans les premières phases de l'affinage. Néanmoins, l'augmentation et l'évolution des acides aminés ainsi que la conséquente protéolyse légère font supposer que ces produits sont utilisés successivement par la flore microbienne constituée pour la plupart des moisissures et levures responsables d'une forte action protéolytique et lipolytique. 
TABLEAU 1

\begin{tabular}{|c|c|c|c|c|c|c|c|c|}
\hline $\begin{array}{c}\text { Mg des acides } \\
\text { aminés/100 g du lait }\end{array}$ & $\begin{array}{c}\text { L. } \\
\text { bulgaricus }\end{array}$ & $\begin{array}{l}\text { Str. } \\
\text { thermo- } \\
\text { philus }\end{array}$ & $\begin{array}{l}\text { Str. } \\
\text { lactis }\end{array}$ & $\begin{array}{l}\text { Str. } \\
\text { cremoris }\end{array}$ & $\begin{array}{l}\text { Str. } \\
\text { diaceti- } \\
\text { lactis }\end{array}$ & $\begin{array}{l}\text { Str. } \\
\text { faecalis }\end{array}$ & $\begin{array}{c}\text { Str. faecalis } \\
\text { var. } \\
\text { liquefaciens }\end{array}$ & $\begin{array}{l}\text { Contrôle } \\
\text { témoin }\end{array}$ \\
\hline Acide aspartique & 1,099 & & 0,305 & & 0,071 & 0,130 & 0,990 & 0,221 \\
\hline Thréonine & 0,540 & 0,628 & 0,066 & 0,550 & 0,111 & 0,570 & 1,666 & 0,077 \\
\hline Sérine & 2,504 & 0,139 & 0,133 & 0,115 & 0,317 & 0,295 & 0,743 & 0,066 \\
\hline Asparagine + Glutamine & 0,410 & 0,304 & 0,399 & 0,430 & 0,522 & 0,256 & 0,511 & 0,032 \\
\hline Sarcosine & & 0,157 & 0,186 & 0,067 & + & + & & + \\
\hline Proline & 4,504 & 1,252 & 0,979 & 1,274 & 1,040 & 1,335 & + & 0,217 \\
\hline Acide glutamique & 7,514 & 0,492 & 2,687 & 2,305 & 3,376 & 1,185 & 0,548 & 5,171 \\
\hline Glycine & 2,663 & 0,139 & 0,024 & 0,082 & 0,058 & 1,023 & 0,857 & 0,754 \\
\hline Alanine & 1,094 & 3,911 & 1,272 & 4,130 & 1,205 & 3,658 & 2,302 & 0,260 \\
\hline Valine & 3,840 & + & 0,013 & 0,009 & 0,013 & 3,333 & 2,148 & 0,112 \\
\hline Cystine & & & & & & & 4,113 & \\
\hline Méthionine & 0,899 & & & & & 0,768 & 1,488 & + \\
\hline Isoleucine & 1,843 & 0,184 & 0,143 & 0,239 & & 0,921 & 2,505 & 0,056 \\
\hline Leucine & 5,708 & 0,007 & 0,007 & 0,011 & 0,100 & 6,055 & 11,297 & 0,058 \\
\hline Tyrosine & 2,560 & 0,138 & 0,104 & 0,158 & 0,029 & 0,051 & 5,402 & 0,070 \\
\hline Phénylalanine & 2,079 & 0,333 & 0,344 & 0,465 & 0,319 & 3,493 & 2,041 & 0,043 \\
\hline A. $\alpha$ aminobutyrique & 0,030 & & & & & & & \\
\hline A. $\gamma$ aminobutyrique & 0,042 & 0,161 & 0,874 & 0,314 & 0,074 & 10,347 & + & 0,041 \\
\hline Ornithine & 0,056 & 0,023 & 0,051 & 0,025 & 0,043 & 0,039 & 4,883 & 0,044 \\
\hline Ethanolamine & & 0,177 & 0,247 & 0,122 & 0,250 & 0,087 & & 0,305 \\
\hline Lysine & 3,135 & 0,031 & 0,056 & 0,056 & 0,069 & 0,518 & 0,524 & 0,181 \\
\hline Histidine & 0,640 & 0,012 & 0,064 & 0,044 & 0,021 & 0,282 & 0,882 & 0,039 \\
\hline Tryptophane & 1,178 & & & & & & & \\
\hline Arginine & 1,754 & 0,014 & 0,015 & 0,012 & 0,041 & 0,264 & 0,387 & 0,692 \\
\hline
\end{tabular}


Il nous faut toutefois maintenir une seule réserve qui concerne quelques souches de Streptococcus faecalis, où les caractéristiques protéolytiques sont macroscopiquement identiques à celles du Pénicillium. Nous nous réservons donc de contrôler dans un prochain travail si les produits de dégradation de la caséine dûs au Streptococcus faecalis sont similaires à ceux dûs au Penicillium.

\section{$R$ é s u m é}

On a pris en considération les caractéristiques protéolytiques de quelques souches de ferments lactiques qu'on trouve ordinairement dans les fromages persillés.

Quelques souches de Str. faecalis se sont montrées particulièrement protéolytiques en attaquant le lait à peu près comme le Penicillium roqueforti. Par conséquent les auteurs se proposent d'étudier, dans un prochain travail, si les produits de dégradation de la caséine dûs aux streptocoques fécaux sont similaires à ceux dûs au Penicillium.

\section{S u m m a ry}

The authors have taken into consideration the proteolytic properties of some strains of lactic acid bacteria which are ordinarily found in blue cheeses.

Some strains of Str. faecalis have proved particularly proteolytic and attack the milk very much in the same way as does Penicillium roqueforti. The authors, therefore, intend to examine in a future study whether the degradation products of casein due to the fecal streptococci are similar to those due to Penicillum.

\section{Bibliographie}

[1] Miller (Ilse), Kandler (O.) (1967). - Milchwissenschaft, 22 (3), p. 150-59.

[2] DolezaleK (J.) (1967). - Sb. Vys. Chem.-thecnol Praze, E 15, p. 59-67.

[3] Knaut (T.), Karnicka (H.), Usajewicz (I.) (1966). - XVIIInt. Dairy Congr. D., p. $515-522$.

[4] Miller (Ilse), KandleR (O.) (1967). - Milchwissenschaft, 22 (10), p. 608-15.

[5] Annibaldi (S.) (1970). - Scienza e Tecnica Lattiero-Casearia, XXI (I), p. 27-34.

[6] Bianchi-Salvadori (B.) (1969). - Scienza e Tecnica Lattiero-Casearia, XX (I).

[7] Salvadori (P.), Bianchi (B.), Cavalli (V.) (1962). - XVI Congrès Int. Lait., B, p. $455-463$.

[8] Salvadori (P.), Bianchi (B.), Cavalli (V.) (1962). - Il Latte (I), p. 18-22.

[9] Salvadori (P.), Bianchi (B.), Cavalli (V.) (1964). - Le Lait, tome XliV, p. $129-138$.

[10] Salvadori (P.), Bianchi (B.) (1967). - Le Lait, $\mathrm{n}^{\circ} 469 / 470$, p. 605-611.

[11] Moore (S.), Stein (W. H.), Spachmann (D.) (1958). - Anal. Chem., 30, p. 1185.

[12] Moore (S.), Stein (W. H.), Spachmann (D.) (1958). - Anal. Chem., 30, p. 1190.

Reçu pour publication en février 1971. 